\title{
Investigation of the Diffusion Impedance for an Irreversible Redox Reaction
}

\author{
M. Chitra Devi ${ }^{1}$, P. Pirabaharan ${ }^{1}$, Michael E.G. Lyons ${ }^{2}$, L. Rajendran ${ }^{3, *}$ \\ ${ }^{1}$ Department of Mathematics, Anna University, University College of Engineering, Dindigul, India \\ ${ }^{2}$ School of Chemistry \& AMBER National Centre, University of Dublin, Trinity College Dublin, \\ Dublin 2, Ireland \\ ${ }^{3}$ Department of Mathematics, AMET (Deemed to be university), Kanathur, Chennai, \\ *E-mail: raj_sms@ rediffmail.com
}

doi: $10.20964 / 2021.06 .44$

Received: 8 March 2021 / Accepted: 14 April 2021 / Published: 30 April 2021

Simple reactant diffusion can be analysed reliably over a finite diffusion layer. The diffusional impedance may be affected by issues arising from homogeneous reactions, variable properties, or ionic migration, and hence more detailed research is needed. The proposed finite-layer impedance model is based on a nonlinear system of equations that includes a nonlinear term related to the diffusion layer's homogeneous reaction. An analytical method is applied to solve the non-steady-state nonlinear equations. The approximate closed-form of analytical expression corresponding to the diffusion-layer impedance has been derived.

Keywords: Impedance, Reaction-diffusion, Nonlinear equations, irreversible homogeneous reaction.

\section{FULL TEXT}

(C) 2021 The Authors. Published by ESG (www.electrochemsci.org). This article is an open access article distributed under the terms and conditions of the Creative Commons Attribution license (http://creativecommons.org/licenses/by/4.0/). 